\title{
John Dewey vs. Confucius: Similarities and Differences in Their Educational Thoughts
}

\author{
Kexin $\mathrm{Xu}^{1, *}$ and Xiaona Wang ${ }^{1}$ \\ ${ }^{\text {I} S c h o o l ~ o f ~ E n g l i s h, ~ T i a n j i n ~ F o r e i g n ~ S t u d i e s ~ U n i v e r s i t y, ~ T i a n j i n ~ 300202, ~ C h i n a ~}$ \\ *Corresponding author. Email: xukexinlq@outlook.com
}

\begin{abstract}
This study aims to compare the similarities and differences in the educational thoughts of Dewey and Confucius. To start with, this study examines their shared opinions on education's function to improve the state of society, education's essence of transferring experience, and practice's central role in teaching process. Then this study explores their diverged educational thoughts regarding the goal of education, the mode of education, and the role of teachers. First, Confucius proposes that education has an ultimate goal of cultivating people with virtues while Dewey believes that educational goal should be continually adjusted and upgraded based on students' expectations. Besides, Confucius promotes a text-centred learning approach and regards the wisdom of the sage as the root of knowledge while Dewey emphasizes a student-centred education mode and believes that knowledge is sourced through the process of inquiry and independent thinking. Furthermore, Dewey regards teachers as facilitators whereas Confucius considers them, except for facilitators, also as role models. It is hoped that this study can provide insights into the development and integration of Chinese and Western education based on the in-depth analysis of the aforementioned sections. Keywords: The educational thoughts of Dewey, The educational thoughts of Confucius, Similarities,
\end{abstract}

\section{Dissimilarities}

\section{INTRODUCTION}

Regarded as 'an exemplary teacher for all ages' [10], Confucius has substantially influenced the history of education in China for over two thousand years. Similarly, John Dewey has profoundly impacted the western educational system and beliefs. He was considered one of the top three educators in the history of western education, alongside Plato and Rousseau. Both Confucius and Dewey engaged in educational practice and founded schools in which to practice and teach their educational theories. The integration of Chinese and Western cultures has highlighted 'the affinity and similarity in educational thoughts between John Dewey's Pragmatism and Confucianism' [6]. However, despite their educational theories sharing similarities, disparity arose from ideas that stemmed from their different philosophies. A comparative study of these two great educators' educational thoughts which root in Chinese traditional thought and Western modern philosophy respectively, would have a significant enlightening effect on the exchange of Chinese educational culture and Western educational cultures.

\section{SIMILARITIES}

\subsection{The Function of Education}

Dewey and Confucius both regarded education as a tool for improving social conditions and promoting social progress [9]. Their shared educational outlook developed from their respective historical and cultural contexts. Following the American War of Independence and the American Civil War, the United States gradually removed obstacles that obscured the path of capitalist development. As a result, the country was in a period of large-scale expansion and transformation by the end of the 19th century. However, spiritual culture did not advance at the same rate as material wealth, the growth of which impacted negatively on the spiritual development of the populace. As such, American society sought a philosophy representative of their national spirit. In this context, Dewey developed pragmatic philosophy and educational theories [1]. This marked the opposition of the United States against traditional European ideas about education, with educational thought adapted to meet the current needs of American modernity and capitalism. Through these theories, Dewey sought to build a democratic society that would enable individuals to freely develop and adapt to different social needs. Dewey advocated bourgeois reformism, hoping to replace violent conflict with the 
wisdom of cooperation by utilizing education as the primary tool for improving society. Dewey believed that education moderated the process of achieving a shared social consciousness, and that the only reliable method of social transformation was to adapt and align individual activities with this social consciousness.

The educational thoughts of Confucius promoted similar ideas. During the Spring and Autumn Period, Confucius was deeply troubled by the brutal rule of slave-owning nobles, issuing the lament, 'tyranny is fiercer than a tiger' ( 苛政猛如虎). The hierarchical system in this period was strict, with the upper class unconcerned by the lives of the lower classes, who they neglected to extreme misery. As a civilian, Confucius wanted to address the chaos in his society by offering the common people the opportunity to participate in politics, through which he could realize his ambition of 'ruling by benevolence and morality' (仁政德 治). He proposed a reform measure that determined 'a good scholar can become an official' (学而优则仕), highlighting his objective to cultivate people of virtue and ability. By promoting those who could govern the country more wisely through education, the 'absence of right principles throughout the country' (天下无道) could be countered [9]. 'Recruiting talented people' (举贤), which means cultivating talents, was an example of this reform. This ideology of liberation reflected the enthusiasm of the intellectuals to participate in the political reform movement during the transition from slavery to feudalism in the late Spring and Autumn Period.

\subsection{The Essence of Education}

A further viewpoint shared between the two philosophers was the transfer and communication of experience being the essence of education [5]. A central strand of the educational philosophy promoted by Dewey responds to human society constantly changing, with Dewey believing that education lied in the continuous transmission of experiences. These experiences referred to social norms, including the knowledge necessary for individual survival and the transmission of social ideals, expectations, standards, and opinions. The brevity of an individual's life necessitated passing down these experiences to a new generation through education. Hence, Dewey argued that the central impact of education occurs through the socialization of minors, which followed two main principles. Firstly, that school was a simplified social life, meaning the process of children being taught in school was actually a process of socialization in a smaller community. Secondly, the socialization process in school taught children various skills, knowledge and habits but, more importantly, also taught them to accept the guidance and cultivation of democratic concepts. This was key because democracy was not only a form of government but also a unified way of life through which experiences can be shared.

Educational ideas similar to those promoted by Dewey were expressed by Confucius over two thousand years before. Confucius referred to the transmission of experiences as Hong Tao (弘道), which means the inheritance of the etiquette system from the previous dynasty [10]. The cultural traditions of the Xia, Shang, and Zhou Dynasties formed the basis for Confucius' Tao. He stated that, 'Zhou had the advantage of viewing the two previous dynasties. How complete and elegant its regulations are! I follow Zhou' (周监于二代, 郁郁乎文 哉! 吾从周). He referred here to the Zhou Dynasty inheriting the etiquette system from the Xia and Shang second generations and, subsequently, his own inheritance of the system from the Zhou Dynasty.

Regarding their shared idea of education meaning the inheritance and continuation of social life, both Dewey and Confucius determined that this occurrence was not an unchanging custom but rather a renewal and creation [1] In Dewey's view, education was taught not only through delivery but also communication. He perceived this communication as a process of sharing experiences, which can impact on the inclinations of those involved. This means the recipient with whom the experiences have been shared can expand or improve on the experience of others, rather than simply copying them. Similarly, the Tao to which Confucius adhered was not a definite and unchangeable eternal social law. Rather than cultural inheritance being passed down the generations and remaining the same, it became a combination of accumulated experiences from previous generations and the existing experiences of the recipient [7]. The theoretical origin of Tao promoted by Confucius came from the etiquette of the Duke of Zhou, but Confucius modified and developed it to make it relevant within his own time period. For example, he removed the Duke of Zhou's view of destiny and integrated in his own teachings the external etiquette system and the idea of internal benevolence, promoting the social system order and the cultivation of personal morality.

\subsection{The Importance of Practice}

Dewey and Confucius both emphasized the importance of practice in the education process. Dewey believed that school was society, meaning school should encompass wider social ideas and the learning that takes place both inside and outside of school should be connected. Furthermore, he believed that, alongside traditional educational subjects, students should be taught ways in which to live, grow and flourish in future society [11]. He emphasized the direct and subjective experience of the learner, encouraged the personal exploration of students, and placed value on practical knowledge. Dewey's principle of 'learning by doing' was reflected in his discussion of teaching methods. He criticized the traditional teaching method proposed by Herbart, which attaches significant importance to the teaching content in books but fails to recognize the advantages of learning through activity [3]. To solve this problem, Dewey designed the Five Steps of Thinking, which encourages 
students to solve problems through critical thinking, a process through which experience was effectively acquired [1].

Although Confucius did not clarify through theory the practicality of teaching activities, he focused on combining teaching and practice through the utilization of concrete and vivid examples to demonstrate his educational ideals. For example, Confucius said in The Analects of Confucius: Zilu: "Though a man may be able to recite the three hundred odes, yet if, when entrusted with a governmental charge, he knows not how to act, or if, when sent to any quarter on a mission, he cannot give his replies unassisted, notwithstanding the extent of his learning, of what practical use is it?' (诵诗三百, 授之以政, 不达; 使于四方, 不 能专对。虽多, 亦奚以为。) It can be seen from this example that Confucius advocated applying knowledge into real cases, accentuating the importance of students' practice of what they have learned [10].

\section{DIFFERENCES}

\subsection{The Goal of Education}

Confucius stressed the necessity of people striving to achieve noble character, with their behaviour embodying their virtues. He emphasized that a person does not need to be a wise leader and may come from all walks of life, but that they must align their identity with the things they do and the qualities they possess and display. Regarding this, Confucius proposed that the ultimate goal of education was to equip students with the skills and motivation needed to achieve their aim of becoming a person of noble character [3]. This idea was based on the social role of hierarchy. Confucius believed that society should be led by a wise leader who can make decisions, with each person playing particular yet various roles and each role having specific requirements and virtues. A person could be an official, a father, a son, a neighbour and so on. The multifaceted nature of a person stemmed not from their interests, concerns, values or goals, but from their position as an individual with multiple social roles and their adherence to the specific virtues imposed on each role.

In contrast, Dewey believed that education had no ultimate goal. Once each goal was achieved, education became a means for people to set and pursue new goals. As with many other practices, education should be guided by an expected goal, with continual corrections and adjustments made in the process of achieving this goal [2]. When a more achievable or better calculated choice appeared, or unexpected flaws were discovered in the original goal, the educator should revise the original ambition. In addition, the expected goal needed to be clearly expressed and explained in detail to make it more concrete [3]. For example, if a student's goal was to learn English, they must pinpoint whether that means speaking fluent English, reading academic English, learning American or British
English, or something else entirely. By clarifying their learning goals and devising a comprehensive plan, students could learn effectively and achieve their desired results.

\subsection{The Mode of Education}

Despite the similarities in their educational thoughts, Dewey and Confucius both emphasized different ideas regarding the mode of education. Dewey advocated for learner-centred education, believing that knowledge was sourced through the process of learning, or the inquiry itself, rather than the knowledge being the product of learning [6]. Therefore, Dewey believed that learning only occurs when individuals who were encountering challenges source strategies for overcoming the obstacles being experienced. Dewey offered the example of a person who tried to lift a stone but only manages after numerous failed attempts [4]. He used this example to highlight his assertion that education should centre on students as the learning subjects because knowledge stemmed from solving problems, through which new skills were acquired Further to this, Dewey claimed that knowledge generated in the past should be treated in the present as a hypothesis and should thus be empirically tested when later applied in a new setting.

Conversely, Confucius focused on transmitting ideas through a series of traditional learning methods: repetition, practice, and meditation. As such, his mode of education was predominantly text-centred and characterized by rotememorization [5]. Confucius believed that knowledge was sourced from authoritative statements and the wisdom of predecessors, which connected with his educational goals that build on a collection of social rules and inherited conventions. This was demonstrated by the emphasis he placed on the study of five ancient classics, which were typically discussed in his classes: Classic of Changes, Classic of Documents, Classic of Songs, Record of Rituals and Spring and Autumn Annals [5]. Additionally, transcendent knowledge passed down through generations does not require experiments. They were defined instead as 'the Way', such as those mentioned in his dialogues with his disciples: 'the Way of the Former Kings', 'the Way of the Master', and 'the Way of the Heaven' [9].

\subsection{The Role of Teachers}

Aligning with their different ideas regarding the ways in which education should be passed down, Confucius and Dewey developed distinct views on the role of teachers. Dewey said that 'what concerns him, as a teacher, is the ways in which that subject may become a part of experience; what there is in the child's present that is usable with reference to it; how such elements are to be used; how his own knowledge of the subject-matter may assist in interpreting the child's needs and doings, in order that his growth may be properly directed [1].' According to Dewey, the role of the teacher was to facilitate the 
transmission of knowledge to students, but the learning subjects should be the students themselves. Teachers should therefore observe the reactions of students when teaching content in the classroom and set different activities, offering flexibility to the students' acquisition of knowledge.

While Confucius viewed teachers as facilitators, he also regarded successful teachers as role models for students [8] From his perspective, educators were the first individuals from which students developed their ideals or other parts of their personality. During the learning process, students assessed the quality of the knowledge being taught in accordance with the rate of success they observed in their teachers. Perceiving teachers as role models may increase the students' belief in authority, thereby inheriting traditional norms and etiquette. This demonstrated the traditionalist beliefs of Confucius, who tried to educate people according to his ideas regarding what is traditionally right [7].

\section{CONCLUSION}

Fueled by their desires to change the status quo amid turbulent social environments, Confucius and Dewey both believed that education functioned as a tool for social improvement. Additionally, they both regarded education to be best transmitted through experience, the Tao being Confucius' equivalent of Dewey's concept of experience. Furthermore, they both recognized that practice played a central role in teaching activities.

However, Confucius and Dewey held contrasting views regarding the purpose of education. The former proposed the ultimate goal of education to be the cultivation of people capable of developing virtues, while the latter rejected the concept of an ultimate educational goal, believing that goals should be continually and appropriately adjusted. Furthermore, their divergent views about the source of knowledge resulted in their different ideas regarding modes of teaching. Emphasizing that independent learning ability is acquired by students through the process of inquiry, Dewey proposed that teaching activities should be student-centred. In contrast, Confucius promoted a text-centred learning approach and regarded the wisdom of the sage as the root of knowledge, motivated by his desire to transmit traditional norms and customs. Their distinct modes of teaching further resulted in the perception of the different roles assumed by teachers. Dewey regarded teachers as facilitators whereas Confucius considered them, except for facilitators, also as role models.

\section{REFERENCES}

[1] Dewey, John. "Experience and education." The Educational Forum. Vol. 50. No. 3. Taylor \& Francis Group, 1986.

[2] Grange, Joseph. "John Dewey and Confucius: ecological philosophers." Journal of Chinese Philosophy 30.3 - 4 (2003): 419-431.

[3] He, Ming Fang. "Exploring an East West epistemological convergence of embodied democracy in education through cultural humanism in Confucius Makiguchi Dewey." Journal of Curriculum Studies 48.1 (2016): 36-57.

[4] Shen, Russell. "Dissimilarities between Deweyan pragmatism and Confucianism." Philosophical Inquiry in Education 20.1 (2012): 24-32.

[5] Sim, May. "Dewey and Confucius: On mora education." Journal of Chinese Philosophy 36 (2009): $85-105$.

[6] Tan, Charlene. "Beyond 'either-or' thinking: John Dewey and Confucius on subject matter and the learner." Pedagogy, Culture \& Society 24.1 (2016): 5574.

[7] Tan, Sor-Hoon. "Confucian democracy as pragmatic experiment: Uniting love of learning and love of antiquity." Asian Philosophy 17.2 (2007): 141-166.

[8] Walker-Coté, Holly. "Comparative Assessment in John Dewey, Confucius, and Global Philosophy." Education and Culture 35.1 (2019): 105-108.

[9] He Yike. "The Dialogue between Chinese and Western Educational Ideas - Taking Confucius and Dewey as Examples." Journal of Lanzhou Institute of Education 35.4 (2019): 72-73,82.

[10] Tao, X. U. "The Educational Philosophy of John Dewey and Confucius: Historical Perspective and Contemporary Significance [J]." Education Science 4.28 (2012): 66-71.

[11] Zhang Yun, \& Yu Peiyuan. "On Dewey's Philosophy of Education and Its Meaning." The Journal of Shanghai Administration Institute, 6.4 (2005): 20-27 